\title{
Use of Magnesium Hydride as Hydrogen Storage Material for Running Cars
}

\author{
Saurabh Kumar Singh \\ Acropolis Institute of Technology and Research, Department of Mechanical Engineering, Manglia chouraha, Indore 452001, India
}

\begin{abstract}
The major energy source today are fossil fuels. But the over-consumption of these fossil fuels is leading to serious environmental issues. When fossil fuels are burnt they release carbon dioxide, sulphur dioxide, carbon monoxide etc.and have severe consequences on habitats. As they are non-renewable sources of energy they are depleting at a rapid rate and their sources are limited, therefore there is a supreme need of alternate fuel which is sustainable. Hydrogen is an alternative fuel that can be produced from various domestic resources and is abundant in our environment. It's stored in water $\left(\mathrm{H}_{2} \mathrm{O}\right)$, hydrocarbons (such as methane, $\left.\mathrm{CH}_{4}\right)$, and other organic matter. One of the challenges of using hydrogen as a fuel comes from being able to efficiently extract it from these compounds. Hydrogen can be produced by splitting water using alloy of Aluminum(with gallium, indium, thallium etc.).Since alloying materials are expensive and the storage of hydrogen according to this process is quite difficult so we found that MgH2 has high hydrogen storage capacity of 7.6 weight\%. This research paper aims on the efficient use of hydrogen for running cars and analysis of its volume that can be stored in cars and also the power developed through it.
\end{abstract}

Keywords: Magnesium hydride, Aluminium, Hydrogen and Cars

\section{Introduction}

In 1951 preparation from the elements was first reported involving direct hydrogenation of $\mathrm{Mg}$ metal at high pressure and temperature (200 atm, 500 deg. C) MgI2 catalyst: [6]

$$
\mathrm{Mg}+\mathrm{H} 2=\mathrm{MgH} 2
$$

On industrial scale $\mathrm{MgH} 2$ powder can be produced. The density of $\mathrm{Mg}$ is one third of Aluminum and it has been used as a lightweight structural material.[2] An ideal hydrogen storage material should have high hydrogen volumetric capacity, ambient reaction temperature for charging/discharging hydrogen and fast kinetics, excellent reversibility, low cost and low toxicity.[3] The problem of poor kinetics of $\mathrm{MgH} 2$ in hydrogen release has been solved by adding hydrolysis process, which can attain hydrogen production yield up to 15.2 mass \% below $100 \mathrm{deg}$. C. Since $\mathrm{Mg}$ is stable in open atmosphere and has no adverse impact on human health [2]; thus it can be used as a storage material for hydrogen. Hydrogen can be also produced by splitting of water when brought in contact with Aluminium alloy.

$$
2 \mathrm{Al}+6 \mathrm{H} 2 \mathrm{O}=3 \mathrm{H} 2+2 \mathrm{Al}(\mathrm{OH}) 3
$$

Since, Aluminium is heavier than Magnesium and the fact of fabricating a different controllable unit for the reaction to produce hydrogen is inevitable.

Also, thermal decomposition reaction of diethyl magnesium MgEt2 (equation 1) and direct hydrogenation (equation 2) are used for the production of $\mathrm{MgH} 2$ [2];

$$
\begin{gathered}
\mathrm{MgEt} 2=\mathrm{MgH} 2+2 \mathrm{C} 2 \mathrm{H} 4 \\
\mathrm{Mg}+\mathrm{H} 2=\mathrm{MgH} 2
\end{gathered}
$$

This gives us reactive $\mathrm{MgH} 2$ that makes handling difficult. Akiyama and co-workers have developed direct hydrogenation process by means of combustion synthesis [4] and hydrogen CVD [5].

Filament $\mathrm{MgH} 2$, and later, granule $\mathrm{MgH} 2$ were successfully synthesized using a hydrogen furnace shown in figure 1 [2]

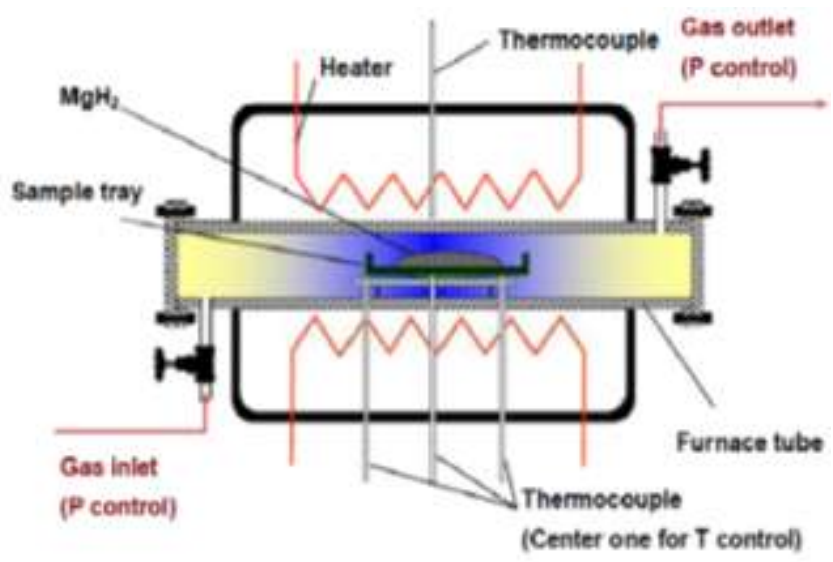

Figure 1: Hydrogen furnance

By decreasing the activation energy, we can enhance the kinetics. For this Nickel and Palladium are well known catalysts for molecular hydrogen dissociation can lower the hydrogenation and dehydrogenation temperature from 275 to $175 \mathrm{deg}$. C and from 350 to $275 \mathrm{deg}$. C, respectively [3].

Since, Magnesium Hydride is found to be a viable hydrogen storage material. $\mathrm{Mg}$ costs $\$ 3.7$ per 100 grams and it is a onetime investment so we can use it to run the cars with hydrogen engine.

\section{Literature Survey}

In early 1780s Alessandro Volta built a toy electric pistol in which an electric spark exploded a mixture of air and hydrogen, firing a cork from the end of the gun.

After that in 1807 Swiss engineer François Isaac de Rivaz built an internal combustion engine powered by a hydrogen and oxygen mixture, and ignited by electric spark. 


\section{International Journal of Science and Research (IJSR) \\ ISSN (Online): 2319-7064 \\ Index Copernicus Value (2016): 79.57 | Impact Factor (2015): 6.391}

In 1860 Belgian Jean Joseph Etienne Lenoir (1822-1900) produced a gas-fired internal combustion engine similar in appearance to a horizontal double-acting steam engine, with cylinders, pistons, connecting rods, and flywheel in which the gas essentially took the place of the steam. This was the first internal combustion engine to be produced in numbers.

In 1892 Dr. Rudolf Diesel developed his Carnot heat engine type motor and in 1893 February 23 Rudolf Diesel received a patent for his compression ignition (diesel) engine.

In 1903 Egidius Elling builds a gas turbine using a centrifugal compressor which runs under its own power. By most definitions, this is the first working gas turbine.

In March, 1937 The Heinkel HeS 1 experimental hydrogen fueled centrifugal jet engine is tested at Hirth.

From 1991 to 2007 Mazda has developed Wankel engines that burn hydrogen.

In 2002 and 2007 BMW tested a supercar named the BMW Hydrogen 7, powered by a hydrogen ICE, which achieved $301 \mathrm{~km} / \mathrm{h}(187 \mathrm{mph})$ in tests. At least two of these concepts have been manufactured.

Earlier the splitting of water is done by Electrolysis, Photoelectrochemical water splitting, Photo-electrocatalytic water splitting and Photo-biological water splitting.

As of 2016, there are 3 hydrogen cars publicly available in select markets; the Toyota Mirai, the Hyundai ix35 FCEV and the Honda Clarity.

Pearl Hydrogen Power Sources of Shanghai, China, unveiled a hydrogen bicycle at the 9th China International Exhibition on Gas Technology, Equipment, and Applications in 2007.

\section{Approach}

We see that the problem of hydrogen storage can be solved by using $\mathrm{MgH} 2$ as hydrogen storage material instead of producing hydrogen on demand in vehicles. $\mathrm{MgH} 2$ readily reacts with water to form hy drogen gas

$$
\mathrm{MgH} 2+2 \mathrm{H} 2 \mathrm{O}=2 \mathrm{H} 2+\mathrm{Mg}(\mathrm{OH}) 2
$$

At $287 \mathrm{deg}$. $\mathrm{C}$ it decomposes to produce $\mathrm{H} 2$ at 1 bar pressure [7].

We can use the hydrogen released to run the cars by filling the fuel tank of cars from filling stations. In normal diesel cars the capacity of fuel tanks ranges from 35 to 50 litres. And we can store $110 \mathrm{~kg}$ of hydrogen per metre cube.

- 1 metre cube $=110 \mathrm{~kg}$ of hydrogen

- 40 litres tank capacity = .04 metre cube

- $1 \mathrm{~kg} \mathrm{H} 2: 142 \mathrm{MJ}=39.4 \mathrm{KWh}$ combustible energy

- $1 \mathrm{~kg} \mathrm{Mg}$ can store 76 grams of hydrogen $=3.0126 \mathrm{KWh}$

- 1 gal $(10 \mathrm{~kg}) \mathrm{MgH} 2$ can store $0.76 \mathrm{~kg}$ of hydrogen

- 1 gal (10 kg) MgH2 makes 30.126 KWh as hydrogen

- 1 gal diesel makes $37.5 \mathrm{KWh}$
Further the kinetic can be enhanced by using shown in the table 1. [3]

Table 1: Magnesium hydrides for hydrogen storage

\begin{tabular}{|c|c|c|c|c|}
\hline \multirow{2}{*}{ Material } & \multicolumn{2}{|c|}{ Temperature ('C) } & \multirow{2}{*}{\begin{tabular}{|c|}
$\begin{array}{c}\text { Max hydrogen } \\
\text { Wt } \%\end{array}$ \\
\end{tabular}} & \multirow{2}{*}{ Reference } \\
\hline & $\mathrm{T}_{\mathrm{s} \text { th }}$ & $\mathrm{T}_{\text {da }}$ & & \\
\hline $\begin{array}{l}\mathrm{MgH}_{2}+10 \mathrm{wt} \% \mathrm{BCC}\left(\mathrm{Ti}_{0,4} \mathrm{CI}_{01}\right. \\
\left.\mathrm{Mn}_{12} \mathrm{~V}_{023}\right)+5 \mathrm{wt} \% \mathrm{MWCNT}\end{array}$ & 300 & 300 & 6 & [1.] \\
\hline 71.5 wt $\% \mathrm{Mg}-23.5 \mathrm{wt} \% \mathrm{Ni}-5 \mathrm{wt} \% \mathrm{Fe}$ & 320 & 350 & $\begin{array}{c}3.32(\mathrm{abs}), 2.42 \\
\text { (des) }\end{array}$ & {$[2]$.} \\
\hline $\begin{array}{l}\text { Mg-14 wt } \% \text { N1-2 wt } \% \text { Fe- } 2 \text { wt } \% \text { Ti-2 } \\
\text { wt } \% \text { Mo }\end{array}$ & 300 & 300 & 4.6 & {$[2]$.} \\
\hline $\mathrm{Mg}-10 \mathrm{wt} \% \mathrm{Ni}-5 \mathrm{wt} \% \mathrm{Fe}-5 \mathrm{wt} \% \mathrm{Ti}$ & 300 & 300 & $\begin{array}{l}5.51 \text { (ads) } \\
5.15 \text { (des) } \\
\end{array}$ & [3.] \\
\hline $\mathrm{MgH}_{2}+10 \mathrm{w} \% \mathrm{TiF}_{3}$ & 300 & 280 & $\begin{array}{l}6.27(\mathrm{abs}) \\
5.98(\mathrm{des}) \\
\end{array}$ & [4.] \\
\hline $\mathrm{MgH}_{2}+10 \mathrm{wt}^{2} \% \mathrm{FeF}_{3}$ & 300 & 280 & $\begin{array}{l}6.33(\mathrm{abs}) \\
4.82(\mathrm{des}) \\
\end{array}$ & [4.] \\
\hline $\mathrm{MgH}_{2}-20 \mathrm{wt} \% \mathrm{AB}_{2}$ alloy & 300 & 300 & 5.7 & [5.] \\
\hline $\mathrm{MgH}_{2}-40 \mathrm{wt} \% \mathrm{AB}_{2}$ alloy & 300 & 300 & 4.1 & [5.] \\
\hline $\mathrm{Mg}-5 \mathrm{wt} \% \mathrm{Ni}-2.5 \mathrm{wt} \% \mathrm{Fe}-2.5 \mathrm{wt} \% \mathrm{~V}$ & 300 & 300 & $\begin{array}{l}5.67 \text { (ads) } \\
4.91 \text { (des) } \\
\end{array}$ & [6.] \\
\hline $\mathrm{Mg}-23.5 \mathrm{w} \% \mathrm{N \textrm {Ni }}-2.5 \mathrm{wt} \% \mathrm{Cu}$ & 300 & 300 & 4 & [7.] \\
\hline $90 \mathrm{Mg}-6 \mathrm{Ni}-4 \mathrm{C}$ & 100 & 250 & $\begin{array}{l}5.23 \text { (abs) } \\
3.74 \text { (des) } \\
\end{array}$ & [8.] \\
\hline $\mathrm{Mg}-14 \mathrm{Ni}-2 \mathrm{Fe}_{2} \mathrm{O}_{5}-2 \mathrm{Ti}-2 \mathrm{Fe}$ & 300 & 300 & $\begin{array}{l}4.56 \text { (ads) } \\
3.32 \text { (des) } \\
\end{array}$ & [9] \\
\hline $\mathrm{Mg}-2 \mathrm{wt} \% \mathrm{MWCNTs}$ & 300 & 300 & $\begin{array}{l}5 \text { (ads) } \\
4 \text { (des) }\end{array}$ & [10] \\
\hline $\mathrm{Mg}-15 \mathrm{wt} \% \mathrm{Ni}-5$ wt $\% \mathrm{Fe}_{2} \mathrm{O}_{3}$ & 300 & 300 & $\begin{array}{l}5.38 \text { (ads), } \\
5.28 \text { (des) }\end{array}$ & [11] \\
\hline $\mathrm{Mg}_{\mathrm{r}} \mathrm{CusNi}_{3} \mathrm{Y}_{\mathrm{l}-\mathrm{X}}$ & 300 & 200 & $\begin{array}{l}4.2-4.5 \text { (abs) } \\
2.6 \text { (des) }\end{array}$ & [12.] \\
\hline $\begin{array}{c}\text { Cat-MgH } \mathrm{MghH}_{2}-5 \mathrm{wt}_{2} \% \mathrm{Nb}_{2} \mathrm{O}_{5}-1 \mathrm{wt} \% \\
\text { Graphite) }+5 \mathrm{w} \% \mathrm{Al} \\
\end{array}$ & 320 & 320 & 5.3 & [13.] \\
\hline $\mathrm{Mg}-10 \mathrm{Ni}-\mathrm{R}(\mathrm{R}=\mathrm{L} \mathrm{a}, \mathrm{Nd}, \mathrm{Sm})$ & 150 & 250 & $35-4$ & [13.] \\
\hline $\mathrm{Mg}-14 \mathrm{Ni}-6 \mathrm{Fe}_{2} \mathrm{O}_{3}$ & 300 & 300 & \begin{tabular}{|l|}
$3.28(\mathrm{ads})$ \\
3.37 (des) \\
\end{tabular} & [14.] \\
\hline $\mathrm{Mg}-10 \mathrm{wt} \% \mathrm{Fe}_{2} \mathrm{O}_{3}$ & 300 & 320 & $\begin{array}{l}4.37 \text { (ads) } \\
0.88 \text { (des) }\end{array}$ & [15.] \\
\hline $\mathrm{Mg}-14 \mathrm{Ni}-2 \mathrm{Fe}_{2} \mathrm{O}_{3}-2 \mathrm{Ti}-2 \mathrm{Fe}$ & 300 & 300 & $\begin{array}{c}.41 \text { (abs) } \\
3.5 \text { (des) } \\
\end{array}$ & [15.] \\
\hline $\mathrm{Mg}-14 \mathrm{Ni}-3 \mathrm{Fe}_{2} \mathrm{O}_{5}-3 \mathrm{Ti}$ & 300 & 300 & $\begin{array}{l}4.00 \text { (abs) } \\
3.98 \text { (des) }\end{array}$ & [15.] \\
\hline $\mathrm{Mg}-23.5 \mathrm{wt} \% \mathrm{Ni}-5 \mathrm{wt} \% \mathrm{Fe}_{2} \mathrm{O}_{3}$ & 320 & 320 & \begin{tabular}{|l|}
$2.69(\mathrm{ads})$ \\
2.27 (des) \\
\end{tabular} & [15.] \\
\hline \multirow{2}{*}{ Matrinal } & \multicolumn{2}{|c|}{ Tequerature ('C) } & \multirow{2}{*}{$\underset{\substack{\text { Nar hydroget } \\
\text { Weth }}}{ }$} & \multirow{2}{*}{ Refintace } \\
\hline & $I_{s}$ & $I_{1=}$ & & \\
\hline 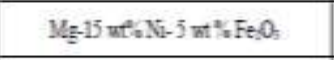 & 300 & 350 & $\begin{array}{l}373(\mathrm{xdk}) \\
332 \mathrm{des})\end{array}$ & [16] \\
\hline ME-145-GFe0,-2MWCATs & 300 & 300 & $\begin{array}{l}292 \text { (adt) } \\
1.75 \text { (des) }\end{array}$ & [17] \\
\hline $\mathrm{Mgh}-5$ urfir $\mathrm{Zral}$. & 250 & 300 & 650 & {$[17]$} \\
\hline $\mathrm{Mg} \mathrm{Ki}_{1} \mathrm{Y}_{3} \mathrm{Pd}$ & 200 & 200 & 44 & [18] \\
\hline $\operatorname{Mg} \mathrm{Ni}_{n} \mathrm{IPE}$ & 300 & 300 & 44 & [19] \\
\hline Mgididaph & 2000 & 200 & 42 & [19] \\
\hline Mgakdapdis & 300 & 300 & 39 & [19] \\
\hline $\mathrm{Mg}, \mathrm{N}_{1}, \mathrm{Y}_{2} \mathrm{Pd}$ & 200 & 200 & 46 & [19] \\
\hline $\mathrm{Mg} \mathrm{Xi}_{1} \mathrm{Ia}_{2} \mathrm{Pl}$ & 300 & 300 & 43 & [19] \\
\hline $\mathrm{MgNa}_{1} \mathrm{Y}_{2} \mathrm{Pd}$ & 200 & 200 & 45 & [19] \\
\hline MgNisurder & 300 & 300 & 42 & [79] \\
\hline $\mathrm{Mg} \cdot 23.5 \mathrm{R}-25 \mathrm{Cu}$ & 300 & 300 & $\begin{array}{l}101(\mathrm{adk}) \\
395(\mathrm{des})\end{array}$ & [19] \\
\hline 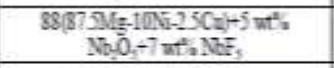 & 300 & 300 & $\begin{array}{l}314 \text { (ads) } \\
151(\text { des) }\end{array}$ & [15] \\
\hline MgH,1aN-IIBH,-2II & 300 & 300 & $\begin{array}{l}4.4(\text { ads }) \\
197(\text { des }) \\
\end{array}$ & [16] \\
\hline $\mathrm{MgCd}$ & 300 & 300 & 28 & [15] \\
\hline Mght-10 unt: Nb,0,-5 ut/。 (EVG) & 310 & 310 & $\begin{array}{l}45(\text { adis }) \\
49 \text { des })\end{array}$ & [15] \\
\hline $\mathrm{Mgh}-10 \mathrm{at} / \mathrm{NB}$ & 300 & 300 & 6 & [15] \\
\hline Ulufie Mg-Tiparties & 400 & 400 & 43 & [15] \\
\hline 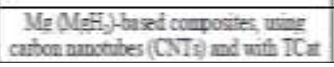 & 200 & 310 & 6 & [16] \\
\hline
\end{tabular}

Theoretically, by using hydrolysis process $\mathrm{Mg}$ can store 15.2 mass \% but practically it can store 6 to 7.6 mass \% of hydrogen.

\section{Volume 6 Issue 12, December 2017}




\section{International Journal of Science and Research (IJSR)}

ISSN (Online): 2319-7064

Index Copernicus Value (2016): 79.57 | Impact Factor (2015): 6.391

\section{Result}

1 gal $(10 \mathrm{~kg})$ of $\mathrm{MgH} 2$ can produce $30.126 \mathrm{KWh}$. This research paper suggests the use of hydrogen efficiently in vehicles and analyses the amount of hydrogen that can be stored in it and the amount of power that can be developed through it. Previous research performed only suggests use of hydrogen in vehicles but not about its storage and utilization.

\section{Conclusion}

The power produced by 1 gal of $\mathrm{MgH} 2$ is less than that produced by 1 gal diesel but the use of $\mathrm{MgH} 2$ is a step forward towards the use of sustainable resources. Also the use of hydrogen as a fuel does not have adverse effect on environment which fossil fuels have such as air-pollution. Using $\mathrm{MgH} 2$ as hydrogen storage material is economical and is viable and also for the betterment of our environment and upcoming generations, we can compromise with the slight lag in power.

\section{Future Scope}

This research paper suggests an alternative hydrogen storage material i.e., $\mathrm{MgH} 2$ for the running of cars without making very large modifications in the design. We have to just replace the diesel engine by hydrogen engine. This paper suggests that instead of using other means for hydrogen storage, we can use $\mathrm{MgH} 2$ and to utilize the hydrogen released in an efficient manner.In future, we may see this method of storage of hydrogen in various other transportation media and also in such machines where hydrogen can be used as a fuel.In this research paper, the analysis has been done by considering the storing capacity of 7.6 mass \% but it may increase in future leading to greater storage amout of hydrogen and further leading to achievement of greater amount of power.

\section{References}

[1] Sushant Puranik and Saurabh Gupta."Efficient Use of Hydrogen Made by Splitting Water by Reaction with Aluminum Alloy".International Journal of Science, Engineering and Technology Research (IJSETR) Volume 2, Issue 10, October 2013

[2] Hiroshi Uesugi*,Takashi Sugiyama, and Isao Nakatsugawa."Production of Hydrogen Storage Material MgH2 and its Applications". BIOCOKE Lab. Ltd., Japan* Corresponding author: uesugih@biocokelab.com

[3] Attuluri.R.Vijay Devunuri,Manisha.D.R, Y.Prashanthi,Ramchander Merugu,Attuluri.J.R.Ravi Teja. "Magnesium Hydrides for Hydrogen Storage: A Mini Review".International Journal of ChemTech Research CODEN (USA): IJCRGG ISSN : 0974-4290 Vol.6, No.7, pp 3451-3455, Sept-Oct 2014.*Corres.author: 202vijay@ gmail.com

[4] H.Isogai,T.Akiyama, and J. Yagi: J.Japan Inst. Metals, 60 (1996) 338-344.

[5] I.Saita,T.Toshima,S.Tanda , and T.Akiyama: J.Alloys and Comp., 446-447 (2007) 82-83.
[6] Egon Wiberg, Heinz Goeltzer, Richard Bauer (1951)."Synthese von Magnesiumhydrid aus den Elementen (Synthesis of Magnesium Hydride from the Elements)".Zeitschrift für Naturforschung B. $\boldsymbol{6} \boldsymbol{b}: 394$.

[7] McAuliffe, T. R. (1980). Hydrogen and Energy (illustrated ed.). Springer. p. 65. ISBN 978-1-34902635-7. Extract of page 65

\section{Author Profile}

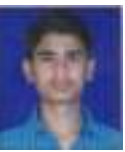

Saurabh Kumar Singh is pursuing Bachelor of Engineering in Mechanical Engineering from Acropolis Institute of Technology and Research 